\title{
nature
}

\section{Steering the future of computing}

\author{
Computational power is surging thanks to insatiable consumers. Natural scientists should seize \\ opportunities to stimulate computer science, to help everybody cope with huge volumes of data.
}

Si ometime in the 2010s, if all goes well, the Large Synoptic Survey Telescope (LSST) will start to bring a vision of the heavens to Earth. Suspended between its vast mirrors will be a threebillion-pixel sensor array, which on a clear winter night will produce 30 terabytes of data. In less than a week this remarkable telescope will map the whole night sky with a greater speed and sensitivity than could have been imagined more than a decade or so ago, recapitulating with added detail the entire history of optical astronomy from Galileo to the Palomar Sky Survey.

And then the next week it will do the same again, looking for transient changes, adding new information and building up a database of billions of objects and millions of billions of bytes.

When looking at the future of scientific computing, as Nature does this week in a selection of News Features and Commentaries (starting on pages 398 and 409), it is easy to focus on the vast data architectures necessary for projects such as the LSST or the Large Hadron Collider at CERN, the European particle-physics laboratory near Geneva. The truly amazing story, though, is of the distributed power that ends up not in exceptional places such as the focal plane of a giant telescope, but spread out across the world; the power that allows data to be acquired from microfluidic chemistry sets and genome sequencers in labs around the world at astonishing rates, and allows the environment - or the human body - to be monitored in real time by vast arrays of sensors. The fact that everyday computing is getting exponentially cheaper promises to vastly increase data flows of all sorts and to revolutionize the practice of science.

It is this remarkable growth that has allowed projects such as the LSST to be imagined - and which will surpass them before they are very old. It is not driven by science, but it has been of immense use to scientists, and will continue to be, if they can change the way science is done to make use of the great potential.

Scientists will increasingly have to rely on automation to extract useful knowledge from these vast data resources. As with computeraided proofs in mathematics, such automation challenges the processes by which scientists gain insight and generate theories. What's more, science will increasingly be done directly in the database, finding relationships among existing data while someone (or something) else performs the primary collecting role. And this means that scientists will have to understand computer science in much the same way as they previously had to understand mathematics, as a basic tool with which to do their jobs.

But scientists can be more than just passive responders to change. Although the great trends in computing are driven by economic and technical forces external to the scientific world, science can provide ideas and challenges that provoke the computer industry into moves it might not have made so quickly on its own. The World Wide Web, after all, grew out of the needs of scientific data users. It was years after Tim Berners-Lee had put his vision of hypertext onto the Internet that it revealed its capacity to revolutionize fields from bookselling to campaign financing.

"Science can provide ideas and challenges that provoke the computer industry into moves it might not have made so quickly on its own."

The computer industry knows that scientists can come up with strange ideas and requirements that may well, in time, have broader commercial application elsewhere. This is one of the reasons why Microsoft is engaging the scientific community with its new 'Towards 2020 Science' report on computers in science (see http://research.microsoft.com/towards2020science). That report inspired this week's focus on computing in Nature. Microsoft is sponsoring free web access to our articles on the subject, although, as always, the content is exclusively Nature's responsibility.

As computing gets ever cheaper, quicker and more powerful, scientists would do well to remember that, by being a demanding and stimulating 'user community' that engages the interest of companies such as Microsoft, Google and Intel, they can influence the development of the field, to everybody's benefit.

\section{A scramble for Africa}

\section{Large dams benefit contractors and corrupt governments morethan they aid the African people.}

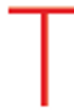
owards the end of nineteenth century, Europe suddenly woke up to the riches that lay in the vast unexplored continent to its south, and the 'scramble for Africa' began. By the start of the First World War, almost all of the continent had been taken by European powers. The rights of Africa's own people, who lost land and many lives during this process, drew scant attention.
Why recall this episode today? Fleetingly, last summer, Africa was big news, when it became the central topic at a meeting in Scotland of the leaders of the $\mathrm{G} 8$ group of top industrialized nations, chaired by British prime minister Tony Blair. Yet the real action is being taken by a donor nation that isn't even a member of the G8: China.

The G8 nations - correctly, if belatedly - are considering how best to invest in Africa, so that the previous misappropriation and mismanagement can be avoided. China seems to have no such qualms. Across the continent, from Zimbabwe to Sudan, China is winning friends by lending money to Africa's most unsavoury regimes without asking awkward questions.

As a News story on page 393 of this issue illustrates, scientists and 
engineers are sometimes complicit with this process. Sudan's Merowe dam on the Nile could be set to repeat the mistakes that have characterized previous large-scale hydropower projects in poor countries. Studies of how to resettle 50,000 people whose land will be flooded, and assessments of the project's environmental impact, were finished late in the day, and undertaken with insufficient rigour. They would have stopped the project going ahead if the World Bank, for example, was funding it.

Lahmeyer International, the German company that is coordinating the project, is disarmingly open about why this is so. It says that funders such as the World Bank make things too complicated. Thorough environmental and social impact assessments take years; Sudan wants power now. China is willing to invest, in part to cement closer ties with an important oil producer. And the Sudanese government lacks the political infrastructure - and probably the political will - to enforce proper safeguards. So, once again, thousands of poor people look set to suffer so that a big dam project can go ahead.

The project's backers have sought to portray Merowe as a necessary trade-off between the competing needs of development and the rights oflocal people. But there is no reason why both needs can't be met. Hydropower certainly has a role to play in Africa's development. Most of the continent's available hydropower resources are untapped and could, if properly harnessed, provide a valuable and renewable source of energy. But that doesn't mean that large dams need to be built. Successful projects in Asia and South America have shown that small hydropower projects can supply a few thousand local people without the need for big resettlement projects. Smaller projects can be run with more input from local people and are easier to combine with other renewable sources, such as solar power.

Unless the lessons of the past are thoroughly learned, large dam projects will sink over time in a morass of corruption, haphazard displacement of local people, lack of political accountability, and failure to plan properly for maintenance.

South Africa has, to its credit, tried to incorporate some of these lessons into a hydropower and water-supply project in Lesotho. The project is imperfect, but at least its administrators have sought to consult with local people and to run independent assessments of its environmental impact. But South Africa, with its wealth "People's rights and needs are once again being sidelined in the stampede for wealth." and its relatively sophisticated political system, is an exception.

In many other African nations, there is little chance of proper safeguards being implemented. Chinese firms and government agencies will operate with few checks or balances. The same goes for the European companies involved in Merowe and elsewhere. They know that rigorous political consultation and environmental assessment are needed if big dam projects are to succeed. Yet they have been happy to engage in such projects in the absence of any such safeguards. The staff and shareholders of these firms are part of another scramble for Africa, in which local peoples' rights and needs are once again being sidelined in the stampede for wealth.

\section{A colourful past}

\section{The production of dyes in the nineteenth century marked a turning point in the appliance of science.}

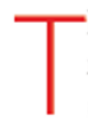
he 150th anniversary of William Perkin's synthesis of aniline mauve dye (see page 429) is more than just an excuse to retell a favourite story from chemistry's past. To be sure, the tale contains much to delight in: Perkin's extraordinary youth and good fortune, the audacity of his gamble in setting up a business to massproduce the dye, and the chromatic riches that so quickly flowed from an unpromising black residue of coal-gas production. But perhaps the most important aspect of the story is the relationship that it engendered between pure and applied science.

The demand for new, brighter and more colourfast synthetic dyes, along with new means of setting them on to fabrics ('mordanting'), stimulated manufacturing companies to set up their own research divisions, and thus cemented interactions between industry and academia that were just developing at the time.

Traditionally, dye-making was a craft, a combination of trial-anderror experimentation and the rote repetition of time-honoured recipes. The idea that chemical production required real scientific expertise did not arise until the eighteenth century, when the complexities of mordanting and multicolour fabric printing moved beyond the expertise of mere recipe-followers.

That was when the Scottish chemist William Cullen announced that if the mason wanted cement, the dyer a dye and the bleacher a bleach, "it is the chemical philosopher who must supply these". Making inorganic pigments preoccupied some of the greatest chemists of the early nineteenth century, notably Nicolas-Louis Vauquelin, Louis-Jacques Thénard and Humphry Davy. Perkin's mauve, however, was an organic compound and so, in the mid-nineteenth century, was rather more mysterious than metal salts. The drive to understand the molecular structure of carbon compounds during this period is often presented today as 'pure' chemistry, but in reality it owed much at the time to the profits that might ensue if the molecular secrets of organic colour could be unlocked.

Both the need to understand molecular structure and the demand for synthetic methods were sharpened by chemists' attempts to synthesize indigo
"Dye companies, including Bayer, Ciba and Geigy, had seen the value of havinghighly skilled chemists on their payroll." and alizarin (the natural colour obtained from the madder plant). When Carl Graebe and Carl Liebermann found a route to making alizarin in 1868, the Badische dye company, soon to become BASF, quickly acquired the rights. One of those who found a better route in 1869 was Ferdinand Riese, who was already working for Hoechst. Another was Perkin.

These and other dye companies, including Bayer, Ciba and Geigy, had seen the value of having highly skilled chemists on their payroll - something that was even more evident when they branched into pharmaceuticals early in the twentieth century. Thus, today's integration of scientific research into industry first began to take shape, as companies realized that good business needs good scientists. 